\title{
¿Es posible enseñar a Roberto Bolaño? Dificultades, RETOS Y POSIBILIDADES DESDE LA DIDÁCTICA DE LA LITERATURA
}

\author{
Alfonso Vargas Franco ${ }^{1}$ \\ Universidad del Valle, Colombia
}

\begin{abstract}
Resumen: Leer a Bolaño plantea una serie de dificultades y retos, pero también de posibilidades para la didáctica de la literatura. Por esta razón, nos planteamos desde esta perspectiva de enseñanza e investigación varias preguntas sobre las cuales ofreceremos algunas aproximaciones que contribuyan a disfrutar y comprender una de las obras de la literatura latinoamericana y universal más heterodoxas y provocadoras: ¿Es posible enseñar a Roberto Bolaño? ¿En qué niveles escolares podría emprenderse la enseñanza de la literatura de Bolaño? o ¿su enseñanza solo podría orientarse a los estudiantes de licenciatura en letras en la educación superior? ¿Qué textos de Bolaño serían más o menos "enseñables" para las nuevas generaciones dentro del proyecto del alumno?

Entre nuestras primeras conclusiones argumentamos que la gran complejidad de las obras mayores como Los detectives salvajes y 2666 las haría inaccesibles para estudiantes de bachillerato, pero que sus poemas, sus ensayos y cuentos, y una novela breve como Estrella distante podrían constituir una puerta de entrada a su obra. Finalmente, proponemos un tema aglutinador como proyecto didáctico: el estudio de la vocación del escritor, que en los textos de Bolaño está cargada de una connotación de aventura salvaje por países, culturas y luchas interiores lo cual lo acercaría mucho a los jóvenes de esta época.

Palabras clave: enseñanza de la literatura; literatura latinoamericana; novela breve; proyecto del alumno.
\end{abstract}

Recibido: 28 de junio de 2019

Aprobado: 12 de agosto de 2019

\footnotetext{
${ }^{1}$ Alfonso Vargas Franco Dr. en Comunicación Lingüística y Mediación Multilingüe, Universidad Pompeu Fabra. Profesor del Departamento de Lingüística de la Escuela de Ciencias del Lenguaje de la Universidad del Valle. Áreas de investigación: Nuevos estudios de literacidad, literacidades digitales, literacidades académicas y formación docente en lenguaje. Correo electrónico: alfonso.vargas@correounivalle.edu.co
} 


\title{
Alfonso Vargas Franco
}

\section{Is it possible to teach on Roberto Bolaño? Difficulties, challenges and possibilities from the teaching of literature}

\begin{abstract}
Reading Bolaño poses a series of difficulties and challenges, but also of possibilities for the didactics of literature. For this reason, we propose from this perspective of teaching and research several questions on which we offer some approaches that contribute to enjoy and understand one of the most heterodox and provocative works of Latin American and universal literature: Is it possible to teach on Roberto Bolaño? At what school levels could this adventure be undertaken? Or could the teaching only be aimed at Bachelor of Arts degree students in higher education? What texts by Bolaño would be more or less "teachable" for the new generations in the context of a student's project? Among our first conclusions, we argued that the great complexity of major works such as The Savage Detectives and 2666 would make them inaccessible for high school students, but that their poems, essays and short stories, and a short novel such as Distant Star could be a gateway to his work. Finally, we propose a unifying theme as a didactic project: the research on the vocation of the writer, which in Bolaño's texts is enriched with a connotation of wild adventure through countries, cultures and internal struggles, which would bring him closer to the young people of this era.
\end{abstract}

Keywords: Latin American literature; student's project; short novel; teaching of literature.

\section{Introducción}

La publicación de Los detectives salvajes (en adelante LDS), Premio Herralde de Novela (1998) y Premio Rómulo Gallegos (1999), y 2666, sus dos novelas mayores en extensión y experimentalismo (hibridación entre diversos géneros literarios, digresiones frecuentes, diálogo entre diferentes voces, ruptura con las figuras dominantes del campo literario en México, denuncia de los feminicidios de Ciudad Juárez, etc.) convirtieron a Roberto Bolaño en un autor de culto y en el escritor más influyente en lengua española después del Boom latinoamericano.

Se trata de obras que tienen vocación totalizadora, pero cuya eclosión tuvo una preparación previa dentro del conjunto de su producción literaria (poemas, cuentos, ensayos, artículos en la prensa, entrevistas, etc.). Sus protagonistas son, en su gran mayoría, escritores jóvenes, poetas especialmente, que reflexionan de manera permanente 
y profusa, entre otros problemas de la existencia, sobre el canon y la creación literaria.

Sin embargo, son las obras "menores" en extensión las que constituyen, a nuestro juicio, los textos que podrían mediar mejor las prácticas en enseñanza de la literatura de Bolaño en el trabajo con lectores adolescentes. Esta selección está conformada por sus ensayos de Entre paréntesis (en adelante EP), breves piezas en las que se mezclan la crítica literaria, la crónica periodística, la autobiografía, el cuento y el poema y las cuales rezuman su credo literario, sus gustos, sus fobias, y sus preferencias en materia de autores dentro de una concepción de escritura híbrida en torno al ensayo y la ficción (Bejarano).

En esta antología también incluimos su Poesía reunida (en adelante PR), publicada en forma póstuma, que recoge el conjunto de su obra poética, pasando por algunos de sus libros de cuentos El secreto del mal (ESM), Llamadas telefónicas (L1T), Putas asesinas (PA) y El gaucho insufrible, (GI); y una de sus obras breves más reveladoras de su poética, Estrella distante (en adelante ED). Así mismo, hay que incluir en esta enumeración el que Bolaño consideró su mejor libro, Amberes, un conjunto de prosas poéticas o poemas narrativos dentro de una novela, aparentemente inconexa, casi onírica, que perfectamente puede leerse como un homenaje a Kafka, uno de sus autores preferidos.

Así, van emergiendo temas relevantes en el estudio sobre Bolaño: ¿Qué hay detrás del mito de Bolaño? y el leitmotiv de la reescritura de algunas de sus novelas. Por ejemplo, Estrella distante es la reelaboración del capítulo final de La literatura nazi en América mientras que Monsieur Pain es la reescritura de La senda de los elefantes, así como Amuleto lo es del capítulo 14 de Los detectives salvajes (Manzoni 61). Finalmente, un asunto central en Bolaño es el del poeta como héroe o como hombre completo o representativo (Emerson 407), asociado con la importancia del valor (Rodríguez 23).

En cualquier caso, su obra produjo un fenómeno editorial y de crítica, no experimentados con otro autor en lengua española en las dos últimas décadas. Este hecho, aunado a la desaparición temprana del escritor, ha contribuido a la consolidación del mito. Este se ha fundamentado, por un lado, en las estrecheces económicas de Bolaño en el comienzo de su 
carrera, que lo llevaron a realizar los oficios más disímiles (vigilante nocturno en un camping en Castelldefells, vendedor en un mercado de artesanías, empleado en un hotel, escritor a destajo para ganar concursos literarios, etc.), y por el otro, en la enfermedad, personificando muchos de los aspectos que constituyen el fenómeno de la maldición literaria (Zapata 10; Brisette 58) hasta alcanzar la gloria literaria e ingresar con éxito en el mercado editorial después de una relación ambivalente con el mismo (Bourdieu 94), y con la misma institución literaria (Dubois 11).

Esta irrupción de Bolaño en el panorama literario latinoamericano plantea de entrada varias preguntas: ¿qué ocurriría cuando el profesor del área de lengua de lengua y literatura quisiera compartir con sus estudiantes algunas de las emociones y reflexiones que esta obra ha suscitado en él como lector y como ser humano? ¿Cómo despertar en los adolescentes, las alegrías y sorpresas que su lectura provoca? ¿Cómo motivarlos a disfrutar y analizar las principales claves de una obra que ocupa ya un lugar preponderante en la literatura latinoamericana y universal? O como plantea Pennac, "Hay que leer, hay que leer... ¿Y si, en lugar de exigir la lectura, el profesor decidiera de repente compartir su propia dicha de leer?" (79).

Estas preguntas se han explorado poco en la investigación sobre Bolaño. Existe una vasta producción de reseñas, artículos y tesis doctorales sobre diversos aspectos de su obra (la violencia, el mal, el humor y la ironía, la vocación del escritor, el valor, su relación con los poetas malditos, la hibridación de los géneros, las rupturas del canon, etc.); pero no se ha estudiado en profundidad, por ejemplo, cómo aglutinar algunos de los grandes temas de la literatura bolañiana para ser enseñados, así como la lectura de las obras que podrían despertar el interés de leer de los adolescentes en contextos escolares y extraescolares. Este artículo pretende aportar en la construcción de una línea de investigación sobre la enseñanza de la literatura de Bolaño a los adolescentes de los grados noveno a undécimo. 


\section{Presupuestos teóricos de la didáctica de la literatura}

\section{La conversación literaria en las aulas de clases}

Aidan Chambers (El ambiente 20; Conversaciones 28; Dime. Los niños 18), uno de los defensores del enfoque de la conversación literaria en las aulas de clase, sostiene que el primer impulso que tiene la mayoría de la personas que han disfrutado de un texto literario es conversar sobre él con un amigo. La conversación literaria puede adoptar dos formas. Una es la conversación informal, la que se produce entre amigos. La otra, más formal, racional y meditada, es el tipo de conversación que transcurre en las aulas de clase y los seminarios:

Ambos tipos de conversación tienden a llevarnos de regreso al círculo de lectura: queremos leer lo que nuestros amigos han disfrutado y queremos releer los libros que nos interesaron seriamente. Ambos tipos de lectura pueden tener otro efecto: pueden ayudar a convertir el círculo de lectura en una espiral (Chambers, El ambiente 21).

La figura del adulto facilitador también emerge con fuerza para concentrar sobre su acción la selección de los libros con los que se cuenta, la disponibilidad y el acceso de los materiales de lectura; el tiempo propiamente dicho para la lectura (lectura en voz alta, la lectura para uno mismo, etc.) y la respuesta, es decir la conversación en su modalidad formal o informal, la posibilidad de volver a disfrutar lo que ya se leyó al compartirlo con el niño o el adolescente. En la siguiente figura "círculo de lectura" defiende que todo comienza con la selección: la selección de un libro es fundamental antes de que pueda iniciar "la lectura", así como la elección de un tema para conversar es fundamental para estimular cualquier conversación (Chambers, El ambiente 16; Dime. Los niños 15) 


\section{Alfonso Vargas Franco}

\section{Círculo de lectura}

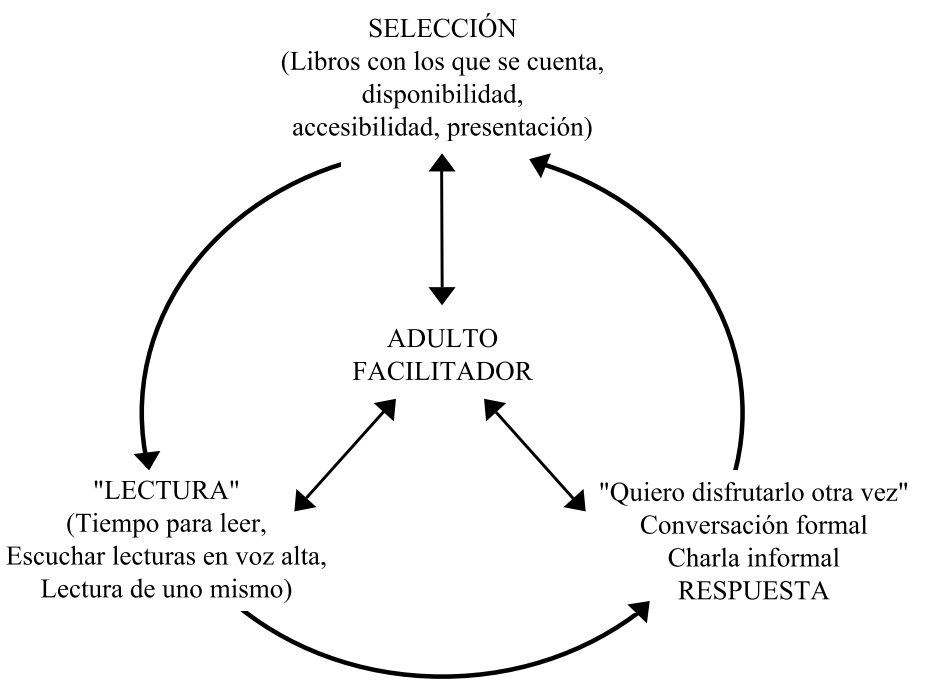

Figura 1. Círculo de lectura. Tomada de (Chambers, El ambiente 15)

¿Es posible enseñar a Bolaño en el contexto de profundas transformaciones de lo escrito?

En consecuencia, inspirados en el "Círculo de lectura" formulamos la pregunta que nos planteamos responder, aunque sin proponer soluciones definitivas: ¿Es posible enseñar a Roberto Bolaño? Es el primer interrogante que habría que plantearse y el cual exige indagar sobre las prácticas de enseñanza de lo literario en la institución escolar, sus condicionamientos ideológicos, sus textos consagrados, sus rutinas, sus válvulas de escape, etc. ¿En qué niveles de la escolaridad podrían producirse encuentros fértiles con su obra? ¿Habría algunos textos "enseñables", más o menos maleables por la didáctica? O, en definitiva, ¿esta obra quedaría solo confinada al estudio de los futuros licenciados en literatura en la educación superior? ¿A los críticos e investigadores? ¿A un pequeño grupo de lectores cultos?

Para continuar proponiendo respuestas a estas preguntas es importante plantear que, el "orden de la lectura" que identificó durante siglos la cultura occidental presenta signos evidentes de disolución, 
tanto en lo relacionado con los procesos de producción y conservación y los de consumo, como consecuencia del desplazamiento del escrito en su formato tradicional, y uno de cuyos principales efectos es la coexistencia del libro con otro tipo de textos audiovisuales, lo cual ha conducido a nuevas prácticas de lectura. Estas se encarnan en un modo de lectura de masas "anárquico, egoísta y egocéntrico" que se basa en un imperativo categórico: "Leo lo que me parece" (Petrucci 442) y que podría asociarse con la capacidad de dispersión de los jóvenes, en detrimento de la concentración, la búsqueda de gratificación inmediata, así como la prioridad conferida a los discursos de las experiencias más emocionales y de narrativas personales situadas y delimitadas (Colomer, Introducción 7).

Sin duda, este "orden de la lectura" ha estallado como consecuencia de la irrupción y la expansión de las tecnologías digitales. Los cambios que están produciendo en la cultura escrita contemporánea son profundos y se examinan sus efectos sobre la lectura en papel y en otros soportes y dispositivos digitales (Kress 19; Barton y Lee 2; Lankshear y Knobel 3; Parodi, Moreno de León, Julio y Burdiles 86).

En este contexto la relación con la literatura y su enseñanza se ve también modificada por estos profundos cambios. Los jóvenes actuales leen y escriben bajo el imperio de la imagen y de las redes sociales, sus gustos en materia de literatura también están permeados por estas profundas transformaciones, a tal punto que las nuevas tecnologías permiten a los consumidores medios "archivar, comentar, apropiarse de los contenidos mediáticos y volver a ponerlos en circulación" (Jenkins 10). Incluso, se ha acuñado el concepto de "comunidades de fans" para explicar las prácticas de adolescentes que leen los libros, van al cine, compran todos los productos del merchandising y desarrollan una intensa actividad en Internet y en las redes sociales compartiendo su afición a algunos libros emblemáticos como Harry Potter o al manga japonés, creando sus propias fanfiction hasta videojuegos en el marco de una "cultura en red" " (Jenkins, Ford, y Green 36; Jenkins 41-42, En, Jenkins, Shresthova, Gamber-Thompson, Kligler-Vilenchik, y Zimmerman 41-42). 
Se produce, entonces, un "espacio de tensión" entre las exigencias escolares y la necesidad de construirse una existencia propia (Colomer, Introducción 9), y la literatura debe responder a las nuevas necesidades de los adolescentes. La densidad y el enorme capital lector (ComptonLilly 73) que exige la lectura de Bolaño constituyen un reto para su enseñanza.

\section{Enseñar los autores difíciles y la formación del lector literario}

Sin embargo, es necesario plantear el debate en torno a la pregunta ¿cómo ayuda un maestro a sus estudiantes a que disfruten libros que al principio les parecen difíciles? Como señala Chambers (Conversaciones $35)$, es necesario plantearse por qué este tipo de preguntas raramente se discute o se considera irrelevante, y es preciso, entonces, ayudar a descubrir cómo leer obras excepcionales y cómo presentárselas a nuestros alumnos. La obra del escritor chileno puede inscribirse en lo que el mismo Chambers denomina escritura "transformacional" (35). En otras palabras, "aquella literatura que, si se lee creativamente, el lector y el autor construyendo juntos la historia, tiene el efecto de transformarnos como lectores y como personas" (35).

En definitiva, consideramos que existen zonas fértiles en la literatura de Bolaño que se pueden explorar por parte de los docentes e investigadores en la enseñanza de la literatura, con el propósito de producir un acercamiento con los estudiantes que pueda conducir a la formación del lector (Colomer, La didáctica de la literatura 130; Colomer, Introducción 8; Colomer, Andar entre libros 37), tal como se propone en la nueva conceptualización de la enseñanza de la literatura como oposición a la historiografía literaria. En efecto, las más recientes innovaciones en la didáctica de la literatura conciben su enseñanza “como un proceso de 'educación literaria' que formará lectores literarios capaces de acceder a una forma de comunicación que usa un lenguaje especial y que transmite un mensaje estético verbal, es decir, lectores con competencia literaria" (Cerrillo 11).

En esta línea, se establece el concepto de lector ideal o la competencia lectora que postulan los propios textos, entre los cuales se pueden destacar los aspectos temáticos o formales, así como también 
de intertextualidad, incluso si estos provocan "la recuperación del esfuerzo de la lectura, y la necesidad de recuperar el texto complejo y con dificultades" (Díaz Plaja 127).

El Lector Modelo (Eco 80) que postulan las novelas "mayores", las novelas "menores", sus ensayos y poemas es alguien que haya leído en profundidad a autores del canon literario como Cervantes, Borges, Bioy Casares, Cortázar, Twain, Joyce, Kafka, Gombrowicz, Malcolm Lowry, Perec, Philip K. Dick, Rulfo, Parra, para citar algunos de los más influyentes en su obra, pero también a aquellos que son objeto de su crítica e ironía como Octavio Paz, Pablo Neruda, José Donoso $\mathrm{y}$, en conjunto, toda la literatura chilena, con muy pocas excepciones, especialmente los imitadores del realismo mágico como Isabel Allende y Antonio Skármetta, contra quienes emprendió un duro trabajo de demolición de su pedestal en el altar literario contemporáneo. Con todo, "Era generoso (a veces demasiado generoso) con jóvenes escritores y muy crítico (a menudo merecidamente crítico) con ciertas vacas sagradas" (Herralde 54).

A pesar de su aspiración de convertirse en novelas "totales", LDS y 2666 también ofrecen vetas de interés para adentrarse en el universo bolañiano: LDS relata la búsqueda detectivesca por ciudades y desiertos de México de una poeta, Cesárea Tinajero, quien desapareció sin dejar el menor rastro y que hace parte del mito literario de los investigadores, dos jóvenes poetas, los fundadores del Infrarrafaelismo, un homenaje a los poetas vanguardistas, Ulises Lima y Arturo Belano, alter ego de Roberto Bolaño, mientras que 2666 es la búsqueda de Breno von Archimboldi, un destacado escritor que decide renunciar a la gloria y la fama del Premio Nobel y huye a México para desaparecer también en forma definitiva mientras una buena parte de la novela documenta los feminicidios de Ciudad Juárez.

En la perspectiva de la educación literaria queremos resaltar el papel del docente como mediador porque constituye uno de los roles fundamentales en la enseñanza de lo literario. Por esta razón, consideramos relevante comenzar a explorar qué papel juega a la hora de enseñar una obra, sobre todo los argumentos que exponen los maestros para elegir los libros que utilizarán con los niños en la institución escolar (Sarland 30). 
En el punto intermedio del triángulo conformado por el lector literario y la formación de la competencia literaria se encuentra el profesor. Como destaca Colomer Entre la normalidad y el desinterés: los hábitos lectores de los adolescentes (Colomer, Introducción 51) en forma reciente se ha venido haciendo énfasis en la relación entre el éxito de la formación lectora del alumnado y la propia actitud de los docentes como profesionales.

\section{Las posibilidades: el proyecto pedagógico}

Sin embargo, en medio de las tensiones pedagógicas en la enseñanza de Bolaño emerge su poesía como una veta muy rica para explorar y que ayuda a conectar con diversas zonas de la obra narrativa de Bolaño, concretamente sus cuentos y novelas. No podemos olvidar que Bolaño ante todo se definía como un poeta. Como señala Herralde:

Bolaño se consideró siempre un poeta. Sólo empezó a escribir narrativa a raíz del nacimiento de su hijo Lautaro, a quien idolatraba, hacia 1990. Pensó que, obviamente, sólo con la poesía no podía soñar con alimentar a su familia, y apenas con la prosa. Sus acrobacias de supervivencia en los primeros 90 , presentándose a toda suerte de premios municipales "premios búfalo" imprescindibles para el escritor piel roja, son el tema de su cuento "Sensini" dedicado al escritor argentino Antonio Di Benedetto, exiliado en España, quien le enseño las tretas de ese arte menor. (21)

En la excelente entrevista "La belleza del pensar" podemos ver a un Bolaño en estado puro. Esta entrevista fue realizada por el periodista y escritor Claudio Sanhueza (https://www.youtube.com/ watch? $\mathrm{v}=40$ pmK0SO-J8\&t=2406s), y en ella Bolaño expone muchos de los secretos de su poética literaria y realiza unas afirmaciones iluminadoras sobre el valor de la poesía en su vida, pero, lo que es más importante aún, reflexiona sobre el significado de la poesía en los adolescentes.

Los argumentos a favor de la poesía como viaje de iniciación -la alusión a LDS es clara- resultan potentes, reveladores de la postura personal del Bolaño poeta, pero también de los sentimientos y expectativas de los adolescentes, especialmente de aquellos que se 
preguntan por el devenir, que experimentan la angustia de la crisis de la identidad en esta etapa crucial de la existencia de cualquier persona. Además, evidencia un conocimiento muy profundo de muchos autores y obras, convirtiendo la entrevista en una apertura a su universo literario.

También constituye una invitación a construir una competencia literaria con un mayor acervo de autores y literaturas porque este es uno de los principales desafíos que propone la poesía y la narrativa de Bolaño. En ellas se mezclan de una manera extraordinaria el fabulador y el crítico en el marco de un conocimiento enciclopédico rico y diverso. Se trata, en todo caso, de un universo que exige una cuidadosa transposición didáctica (Chevallard 39).

\section{Propuesta pedagógica}

Podríamos incluso establecer una comparación que sonrojaría al mismo Bolaño, quien a pesar de su fama de pendenciero era una persona tímida y modesta. Así como Borges afirmó respecto a Quevedo: "Francisco de Quevedo es menos un hombre que una dilatada y compleja literatura", podríamos afirmar que Bolaño es "una dilatada y compleja literatura" (73).

\section{Objetivo de la propuesta pedagógica:}

El objetivo general de la propuesta es iniciar una exploración del universo literario del escritor Roberto Bolaño que permita materializarse en los siguientes subobjetivos:

1. Elaborar un modelo de enseñanza de los contenidos o temas centrales de su obra por medio de la conversación en el aula y que contribuya por un lado a disfrutar, en primer lugar, sus obras ED, PR y EP, y, por el otro, a comprender cómo se ha construido literariamente este vasto y complejo universo poético que llega a la escritura de obras cumbre como LDS y 2666.

2. Profundizar en el conocimiento de la vocación literaria del escritor y como este supera las condiciones más adversas a nivel económico y de su salud para cumplir su deseo de adolescente: convertirse en un poeta. 
3. Explorar en los conceptos nucleares de la obra de Bolaño: el tema del mal y la violencia, el humor, la ironía, el amor, la soledad, la enfermedad, la muerte, la búsqueda detectivesca, la amistad, la poesía, etc.

4. Estimular diversas prácticas de escritura creativa y académica alrededor de la obra de Bolaño.

- En la dimensión creativa de la escritura crear fanfiction con base en algunos de las obras que se estudiarán en el marco de secuencias de aprendizaje.

- Los estudiantes deben escribir también reseñas, comentarios y ensayos sobre algunos de los textos de Bolaño que más les hayan impactado o sobre los cuales se haya profundizado más en la conversación en el aula.

Hemos señalado que la enseñanza de la obra de Bolaño podría comenzar con sus poemas de PR, los cuales, junto con ED, una novela corta, pueden ser los anclajes adecuados para comenzar un recorrido complejo pero fascinante por la poesía, la narrativa, la crítica literaria y la autobiografía del escritor chileno que encontramos en EP.

ED gira alrededor del alter ego de Bolaño, Arturo Belano, y de su amigo Bibiano O'Ryan, con quienes frecuenta los talleres literarios en Concepción (Chile). Transcurrían los años 1971 ó 1972, como plantea el narrador, cuando Salvador Allende era presidente de Chile. En uno de ellos, el de Juan Stein, vio por primera vez a Carlos Wieder, que se hacía llamar antes del golpe de Estado de Pinochet, Alberto Ruuiz-Tagle, un misterioso poeta, autodidacta, silencioso y reservado que ejercía una gran fascinación en las mujeres y una profunda desconfianza en los hombres porque elucubraban que en esa misteriosa y encantadora personalidad se escondía un personaje extraño y perverso.

En los talleres no daba a conocer con exactitud ni su credo poético y mucho menos sus poemas; solo se limitaba a asentir frente a la lectura de sus condiscípulos o a leer, como máximo, algún par de líneas de los suyos mientras seducía con su sola presencia a las bellas hermanas Garmendia. Sin embargo, con el golpe de Estado de Pinochet se reveló su verdadera identidad: Carlos Wieder, un piloto de la FACH (Fuerza Aérea de Chile) que realizaba temerarias maniobras aéreas en 
aviones de reacción mientras escribía en el aire poemas apocalípticos que rendían culto a la violencia y la muerte y anunciaban un nuevo amanecer, propio de los regímenes totalitarios.

Durante la Transición, Wieder huye y su rastro de pierde por completo y se conocen historias terribles como torturas y desapariciones, como las de las hermanas Garmendia, y comienza su búsqueda por parte de Bibiano O'Ryan y de un detective privado, financiado por particulares:

"Y es entonces cuando aparece en escena Abel Romero y cuando vuelvo a aparecer en escena yo. Chile también nos ha olvidado" (ED 121).

El narrador es contratado para contribuir en su búsqueda y acepta porque su situación económica se lo exige. Está pasando por una situación de extrema pobreza y de inactividad creativa y necesitaba sacudirse de este marasmo. Su trabajo consiste en encontrar a través de algún heterónimo al poeta Carlos Wieder y a cambio recibiría un pago de doscientas mil pesetas por parte del detective Carlos Romero. Belano descubre, a través de un ensayo y de un poema, a Wieder en el heterónimo de un par de revistas francesas, "un tal Jules Defolgue" (138).

Finalmente, Wieder es cazado por Abel Romero en Blanes, curiosamente la ciudad en la vivió la etapa final de su vida Roberto Bolaño.

\section{Actividad 1}

Reconstruir, a partir de la lectura de PR y ED el tema de la vocación literaria de Roberto Bolaño:

- Leer los poemas que marcan la iniciación de Bolaño como poeta, identificar sus motivos, sus influencias y su estilo enmarcados en el tema de su formación como poeta y escritor.

- Establecer los vasos comunicantes o las relaciones entre el Bolaño poeta y los poetas "malditos" y vanguardistas (Rimbaud, Baudelaire, Poe, Lautréamont, etc.).

- Leer y comentar en clase la novela ED para seguir indagando en la formación del Bolaño como poeta y escritor, explorando cómo 


\section{Alfonso Vargas Franco}

algunas actividades como los talleres literarios, los amigos y ciertas influencias literarias aportaron en este camino.

\section{Actividad 2}

Con base en la lectura de ED:

- Establecer cómo se evidencian aspectos relacionados con su vocación literaria y sobre su identidad como poeta.

- Identificar temas relevantes en la obra de Bolaño a partir de la lectura de ED:

- Profundizar en el tema del poeta Carlos Wieder, al servicio de la dictadura de Pinochet y las implicaciones éticas del arte al servicio del mal.

- El problema del mal como leitmotiv en varias de sus obras narrativas.

- La amistad y la vocación literaria.

- La poesía.

- Lo policiaco: la figura del detective y la cacería del criminal. ¿Venganza o justicia?

- Explorar las características de la novela de la dictadura en Chile. Establecer un diálogo con La aventura de Miguel Littin clandestino en Chile de García Márquez.

- Consultar sobre la dictadura de Pinochet en Chile y su papel en la vida del escritor.

\section{Actividad 3}

Explorar en la figura del detective en fragmentos de Los detectives salvajes (LDS) y en ED.

- Identificar qué elementos de la novela policiaca se encuentran presentes en ED y LDS.

- Analizar el tema político a partir del desarrollo de ED.

- Consultar en Wikipedia sobre la vida y obra de Bolaño y evidenciar los elementos autobiográficos en ED y PR.

- A la luz de esta pesquisa indagar por qué es tan importante la figura del detective en la vida y obra de Bolaño. 


\section{Actividad 4}

La creación de una comunidad de fans alrededor de Bolaño

- Explorar en diversos aspectos de la vida de Bolaño: su vida en Chile, su estancia en México durante su adolescencia y el comienzo de su vida adulta y cómo esta experiencia mexicana marca definitivamente su vocación y su obra, sus diversos oficios para sobrevivir en Barcelona y su estancia final en Blanes con su esposa y sus hijos, sus viajes, sus luchas para vivir de la escritura, sus gustos musicales, sus escritores preferidos, sus escritores "odiados", sus manías, sus fobias, sus publicaciones, el reconocimiento de la crítica y la gloria literaria, etc.

- Realizar una primera revisión bibliográfica en bases de datos, journals, periódicos y revistas en línea y libros de ensayo sobre los estudios en torno a la obra de Bolaño desde lo más personales (homenajes, reseñas, semblanzas) hasta los más académicos (artículos, trabajos de grado, trabajos de investigación, monográficos y tesis doctorales) para identificar líneas de estudio sobre la obra de Bolaño y principales investigadores (países, universidades), así como el grado de impacto de estas publicaciones (número de citaciones en artículos en revistas indexadas, Google Scholar, Researchgate, etc.).

- Llevar a cabo la curaduría de la página de Wikipedia sobre Roberto Bolaño.

- Crear blogs y wikis para difundir entre adolescentes la obra de Roberto Bolaño.

\section{Actividad 5}

Explorar en torno al mito de Bolaño como escritor infortunado y el fenómeno de la maldición literaria.

- Consultar sobre la vida de Roberto Bolaño, su adolescencia en Chile, su estancia en México, así como su vida en España (Cataluña).

- Indagar en los comienzos de Bolaño como poeta y cómo fue construyendo su vocación arrasadora de escritor.

- ¿Qué oficios tuvo que realizar Bolaño para poder comer y escribir?

- ¿Por qué decidió escribir y publicar de manera desaforada cuentos y novelas cuando siempre afirmó que era ante todo un poeta? 
- ¿Por qué se puede afirmar que Bolaño reprodujo consciente o inconscientemente el mito del escritor infortunado?

- ¿Cómo fue su relación con los editores? ¿Cómo entró en el mercado? ¿Qué supuso esto para su visión romántica del oficio de escribir?

\section{Conclusiones}

Una de las preguntas que nos planteamos al comienzo de este artículo, en la línea del debate abierto por Chambers (Conversaciones, 35), es ¿cómo ayuda un maestro a sus estudiantes a que disfruten libros que al principio les parecen difíciles? Para responderla partimos del presupuesto de que la obra de Bolaño es una obra de culto y su puesta en escena en el aula plantea una serie de retos y dificultades, que hemos analizado en forma extensa en el artículo, lo cual constituye precisamente un reto interesante para la didáctica de la literatura.

Paradójicamente, enseñar a Bolaño abre unas posibilidades interesantes para la formación de los adolescentes como lectores literarios. Los protagonistas de los cuentos y novelas del autor chileno son jóvenes escritores que en forma detectivesca buscan las huellas de poetas y novelistas que desaparecieron misteriosamente y despliegan su propia vocación literaria.

Por otra parte, el mito del genio desdichado o maldito (Zapata 10; Brissette 58) que acompañó a Bolaño en vida y que lo emparenta con otros poetas malditos como Rimbaud, Poe o Baudelaire constituye un objeto de estudio para abordar con los lectores jóvenes. La búsqueda de la identidad y la vocación del escritor devienen en un campo de investigación relevante, vocación que en el caso de Bolaño fue toda una aventura con diversidad de peripecias y vicisitudes (viajes, oficios, elecciones, preferencias literarias, fobias literarias, descubrimientos, manías, etc.) y cuya documentación mostraría lo que hay de fondo en la vida literaria y que muchas veces la academia no estudia en profundidad para comprender una poética literaria.

El éxito literario y económico que alcanzó Bolaño en las postrimerías de su vida es otro tema de investigación interesante desde la perspectiva de la sociología de la literatura. Bolaño estableció unas relaciones ambivalentes con el mercado editorial: fue muy crítico de los premios 
editoriales y escribió polémicos artículos sobre los mismos (Cobas 4358), por ejemplo, el que publicó sobre el Premio Nacional de Literatura de Chile. Sin embargo, Bolaño ingresó luego en el mercado literario de manera muy exitosa, obtuvo diversos premios, el Premio Herralde en 1998 por Los detectives salvajes, y por la misma obra el Rómulo Gallegos en 1999.

Todo lo que hay en esta aventura literaria de Bolaño, estudiado desde dentro de sus obras es, a nuestro juicio, una de las mejores estrategias para enseñar su obra a los adolescentes de hoy.

\section{Referencias}

Barton, David. y Lee, Carol. Language Online. Investigating Digital Texts and Practices. London/New York: Routledge, 2013. 2. Impreso.

Bejarano, Alberto. Ficción e historia en Roberto Bolaño: buscar puentes sobre los abismos. Bogotá: Instituto Caro y Cuervo, 2018. Impreso.

Bolaño, Roberto. Amberes. Barcelona. Anagrama. Narrativas Hispánicas, 2013 [Primera edición, 2002]. Impreso.

Bolaño, Roberto. Cuentos. Llamadas telefónicas. Putas asesinas. El gaucho insufrible. Barcelona: Anagrama, 2014 [Primera edición en "Narrativas hispánicas": 1997, 2001, 2003, respectivamente]. Impreso.

Bolaño, Roberto. Entre paréntesis. Barcelona: Anagrama, 2008 [Primera edición en "Argumentos", 2004]. Impreso.

Bolaño, Roberto. El secreto del mal. Barcelona: Anagrama. Narrativas Hispánicas, 2007. Impreso.

Bolaño, Roberto. Estrella distante. Barcelona: Anagrama, 2007 [Primera edición en "Narrativas Hispánicas", 1996]. Impreso.

Bolaño, Roberto. La literatura nazi en América. Bogotá: Debolsillo. Penguin Random House, 2017. Impreso.

Bolaño, Roberto. Los detectives salvajes (Premio Herralde de Novela). Barcelona: Anagrama: Narrativas Hispánicas, 2004 [Primera edición, 1998]. Impreso.

Bolaño, Roberto. Monsieur Pain. Barcelona: Anagrama, 1999. Impreso.

Bolaño, Roberto. Poesía reunida. Barcelona: Alfaguara, 2018 [Primera edición]. Impreso.

Bolaño, Roberto. La belleza del pensar. Entrevista concedida a Cristian Warnken. Estación Mapocho. Canal UC Cable. 2016. https://www.youtube. com/watch?v=4opmK0SO-J8\&t=399s. Digital. 23, SEPT. 2019.

Bolaño, Roberto. 2666. Barcelona. Anagrama. Narrativas Hispánicas, 2007 [Primera edición, 2004]. Impreso. 
Borges, Jorge Luis. Otras inquisiciones. Madrid: Alianza, 2007. 73. Impreso. Bourdieu, Pierre. Las reglas del arte. Génesis y estructura del campo literario. Barcelona: Anagrama, 1997. 94. Impreso.

Brisette, Pascal. La maldición literaria. Del poeta andrajoso al genio desdichado. Bogotá: Fondo de Cultura Económica/Luna Libros, 2018. 58. Impreso.

Cerrillo, Pedro. El lector literario. México: Fondo de Cultura Económica, 2016. 11. Impreso.

Cobas Corral, Andrea. "En la sala de lecturas del infierno". Poesía Infrarrealista y figuras de escritor en la obra de Roberto Bolaño. Errancia y escritura en la literatura latinoamericana. Ed. Cecilia Manzoni. Jaén: Alcalá, 2009. 4358. Impreso.

Colomer, Teresa. La didáctica de la literatura: temas y líneas de investigación e innovación. La educación lingüistica y literaria en la enseñanza secundaria. Coord. Carlos Lomas, Teresa Colomer, Andrés Osoro y Amparo Tusón. Barcelona: ICE: Horsori, 1996. 123-142. Impreso.

Colomer, Teresa. Introducción: Lectura de frontera y frontera de la lectura. Lecturas adolescentes. Coord. Teresa Colomer. Barcelona: Graó, 2009. 5-16. Impreso.

Colomer, Teresa. Andar entre libros. La lectura literaria en la escuela. México: Fondo de Cultura Económica, 2012. 37. Impreso.

Compton-Lilly, C. "The complexities of reading capital in two Puerto Rican Families". Reading Research Quarterly, 42(1), (2007): 72-98. Digital. 20 Sept, 2019.

Chambers, Aidan. El ambiente de la lectura. México: Fondo de Cultura Económica. 2007. 15-21. Impreso.

Chambers, Aidan. Conversaciones. Escritos sobre la literatura y los niños. México: Fondo de Cultura Económica, 2008. 28-35. Impreso.

Chambers, Aidan. (2012). Dime. Los niños, la lectura y la conversación. México: Fondo de Cultura Económica, 2012. 15-18. Impreso.

Chevallard, Yves. La transposition didactique. Du savoir savant au savoir enseigné. París: Le Pensée Sauvage, 1991. 39. Impreso.

Díaz-Plaja, A. (2009). Entre libros: la construcción de un itinerario lector propio en la adolescencia. Lecturas adolescentes. Coord. Teresa. Colomer. Barcelona: Graó, 2009. 199-150. Impreso.

Dubois, Jacques. (2014). La institución de la literatura. Medellín: Universidad de Antioquia, 2014. 11. Impreso.

Eco, Umberto. Lector in fábula. La cooperación interpretativa en el texto narrativo. Barcelona: Lumen, 1993. 80. Impreso.

Emerson, Ralph Waldo. Obra ensayística. Valencia: Artemisa, 2010. 407. Impreso. 
Herralde, Jorge. Para Roberto Bolaño. Barcelona: Acantilado, 2005. 21-54. Impreso.

Jenkins, Henry. Fans, blogueros y videojuegos. La cultura de la colaboración . Barcelona: Paidós, 2014. 10. Impreso.

Jenkins, H., Ford, Sam. y Green, Joshua. Cultura transmedia. La creación de contenido y valor en una cultura en red. Barcelona: Paidós, 2015. 36. Impreso.

Jenkins, Henry. Youth Voice, Media, and Political Engagement. Introducing the Core Concepts. Eds. Henry. Jenkins, Sangita. Shrethova, Liana. Gamber-Thompson, Neta Kligler-Vilenchik y Arely M. Zimmerman. By Any Media Necessary. The New Youth Activism (p. 1-60). New York: New York University Press, 2016. 41-42. Impreso.

Kress, Günther. Literacy in the New Media Age. London/New York: Routledge, 2003. 19. Impreso.

Lankshear, Colin. Y Knobel, Michele. New Literacies: Changing Knowledge and Classroom Learning. Buckingham: Open University Press, 2011. 3. Impreso.

Manzoni, Cecilia. (2009). Ciencia, superchería y complot en Monsieur Pain de Roberto Bolaño. En Cecilia. Manzoni. Errancia y escritura en la literatura latinoamericana contemporánea. 59-74. Jaen: Alcalá. Impreso.

Parodi, Giovanni, Moreno de León, Tomás., Julio, Cristobal y Burdiles, Gina. "Generación Google o Generación Gutenberg: Hábitos y propósitos de lectura en estudiantes chilenos" Comunicar 58 (2019): XXVII, 85-94. Digital, 20 Sept. 2019.

Pennac, Daniel. Como una novela. Barcelona: Anagrama, 2009. 79. Impreso.

Petrucci, Armando. Leer por leer: Un porvenir para la lectura. Eds. Guglielmo Cavallo y Roger Chartier Historia de la lectura en el mundo occidental Madrid: Taurus, 2011. 425-451. Impreso.

Rodríguez, Franklin. Roberto Bolaño: el investigador desvelado. Madrid: Verbum, 2015. 23. Impreso.

Sarland, Charles. (2003). La lectura en los jóvenes: cultura y respuesta. México: Fondo de Cultura Económica, 2003. 30. Impreso.

Zapata, Juan. (2018). Prefacio. En, Pascual Brisette. La maldición literaria.

Del poeta andrajoso al genio desdichado Bogotá: Fondo de Cultura Económica/Luna Libros, 2018. 9-16. Impreso. 